\title{
PERSPEKTIF INDEPENDENSI DAN BUDAYA JAWA “EWUH PAKEWUH" TERHADAP KINERJA APARAT PENGAWAS INTERNAL PEMERINTAH (APIP) DI SOLO RAYA
}

\author{
Muhrom Ali Rozai \\ Insititut Agama Islam Negeri Surakarta \\ Jl. Pandawa, Dusun IV, Pucangan, Kota Surakarta \\ murhromalirozai@gmail.com
}

\begin{abstract}
The Purpose of study is to test the influence of independence, and local culture "Ewuh Pakewuh" toward the Performance of the regional Inspectorate APIP in Solo Raya. The Methodology of study which is done to 166 internal auditors who work in Regional Inspectorate explored through questionnaire. The analysis which is applied in this study is double regression analysis. The Finding of study reveals significant positive influence between independence and performance. Local culture "ewuh pakewuh", they have negative impacts on the Performance of the regional Inspectorate APIP in Solo Raya. The Limitations of study are; to differentiate between the auditors of the Regional Affairs Implementation, and the research instrument that is adopted from the researches conducted outside Indonesia causes different situation and condition both in public and private sector. The Practical Implication Local culture "Ewuh Pakewuh" should be minimalized in order to improve the auditors" professionalism. The Value of study is important because this study provides contribution of the importance of independence on performance and local culture 'ewuh pakewuh' of the Regional Inspectorate especially who were taken as the samples of this study
\end{abstract}

Abstrak: Tujuan penelitian adalalah menguji pengaruh Independensi dan budaya lokal "Ewuh Pakewuh" terhadap Kinerja APIP Inspektorat daerah di Solo Raya . Desain/Metodologi penelitian ini dilakukan kepada 166 auditir internal yang bekerja di Inspektorat Daerah dieksplorasi menggunakan kuesioner. Analisis yang digunakan adalah analisis regresi berganda. Temuan adanya pengaruh positif signifikan antara independensi dengan kinerja. budaya lokal "ewuh pakewuh" berpengaruh negatif terhadap Kinerja APIP Inspektorat daerah. Keterbatasan sulitnya membedakan antara auditor dan pengawas penyelengara urusan pemerintah derah dan instrumen penelitian yang diadopsi dari penelitian yang dilakukan di luar Indonesia sehingga situasi dan kondisi sektor publik dan sektor privat yang berbeda. Implikasi Praktis Budaya lokal "ewuh pakewuh" hendaknya diminimalisir untuk meningkatkan profesionalsme pengawas. Nilai penelitian ini penting karena memberikan kontribusi pada pentingnya indpendensi pada Kinerja APIP Inspektorat daerah dan budaya lokal "ewuh pakewuh" pada pegawai di Inspektorat daerah terutama pada pegawai yang menjadi sampel penelitian.

Kata Kunci : independensi, ewuh pakewuh, kinerja.

\section{PENDAHULUAN}

Fenomena pengawasan pemerintah daerah terkesan belum dilakukan secara maksimal baik mekanisme maupun implikasi proses pelakasanaan pemerintahan, 
sehingga pemerintah perlu melakukan restrukturisai yang sisitematik baik pada sapek administarsi maupun aspek pengawasannya (Harsudi 2012). Aparat Pengawas Internal Pemerintah (selanjutnya di sebut APIP) sesuai fungsi harusnya dapat sebagai "mata dan telinga" bagi pimpinan atas penyelenggaraan pemerintah apakah sudah dilakukan degan good governance dan clean government. Tetapi keberadaannya maksimal dalam mengawal pengelolaan pemerintahan, ini terjadi karena adanya perbedaan kepentingan memaknai pengawasan internal di satu sisi "melindungi" dan di sisi lain "melakukan koreksi" bagi pimpinan. Hal tersebut tidak terlepas dari proses politik yang tidak sehat dalam pemilihan kepala daerah yang memerlukan banyak biaya, sehingga Independensi APIP akan mejadi pertanyaan masarakat.

Independensi APIP dilihat pada pengambilan keputusan tidak berdasarkan kepentingan pribadi, pimpinan, maupun pihak yang menjadi obyek audit, tetapi berdasarkan fakta dan bukti yang dikumpulkan selama penugasan audit (Agustina 2011). Independensi APIP terlihat karena pimpinan yang baik, Insepktorat akan independen jika penempatan dan penunjukan pimpinan dilakukan dengan benar dan baik. Inspektur mempunyai pernanan penting dalam menciptakan indpendensi bagai APIP, sehingga diperlukan adanaya uji kelayakan dan kepatutan bagi calon Inspektur dari sisi moral, integritas, kompetensi maupun kredibilitas (Harsudi 2012), tetapi kenyataannya Inspektur Inspektorat di tunjuk secara langsung oleh pimpinan daerah tanpa adanya uji kelayakan, intergritas dan kredibilitas. Uji ini harus dilakukan oleh pihak eksternal, bukan dari instansi pemerintah daerah yang bersangkutan, ini bertujuan untuk mendapatkan pimpinan yang memberikan jaminan tugas pokok dan fungsi dari pengawas internal dapat berjalan dengan baik

Aparatur negara dalam tataran birokrasi, yang memiliki orientasi pada kekuasaan (Soeharjono 2011). Birokrasi di mana jabatan dan perilaku dalam keseluruhan hirarki birokrasi lebih didasarkan pada hubungan familier, hubungan pribadi dan hubungan "bapak - anak buah" (patron - client) atau disebut dengan birokrasi patrimonial (Djafar 2012). Budaya patron - klien dapat timbul karena saling kebergantungan antara atasan (patron) dan bawahan (klien) (Yuli 2002), baik karena kedekatan kesukuan dan kekerabatan (ikatan primordial) maupun saling pengertian dalam memandang nilai-nilai dan prinsip kehidupan.

Dalam perkembangan selanjutnya, budaya patron - klien menimbulkan pola perilaku ewuh pakewuh dalam hubungan antara bawahan dan atasan (Soeharjono 2011). Diakui atau tidak, dalam lingkungan birokrasi di Indonesia, budaya ketimuran dalam konteks kesantunan jawa ewuh pakewuh, yaitu sikap sungkan atau rasa segan serta menjunjung tinggi rasa hormat terhadap atasan atau senior masih melekat di banyak pegawai di Indonesia baik kepada pimpinan, sesama pegawai yang lebih senior atau kepada pegawai lainya dengan maksud dan tujuan tertentu. Hal yang demikian akan sulit untuk dihilangkan, sebab ciri individual seperti ewuh pakewuh dapat berubah menjadi ciri massal, manakala rasa ewuh pakewuh bersamaan berkembang menjadi budaya kerja.

Ketika terjadi kesalahan atau penyimpangan yang seharusnya ada konsekuensinya, berlalu begitu saja karena ketidaktegasan di antara anggota instansi pemerintah. Hal yang seperti itu disebabkan ewuh pakewuh yang membuat para 
pejabat birokrat pemegang posisi kunci berada dalam posisi kehilangan kontrol baik oleh pejabat birokrat bawahannya maupun oleh aparat pengawas (Soeharjono 2011). Budaya ewuh pakewuh akan menjadi masalah karena hasil pengawasan yang dilakukan oleh pengawas inspektorat kemungkinan tidak memperlihatkan hasil yang sebenaranya, ewuh pakewuh menjadikan sistem pengendalian intern menjadi tidak efektif (Soeharjono 2011) dan ewuh pakewuh dapat mempengaruhi teguran dari atasan kepada bawahan (Wibowo et al. 2013). Efek ewuh pakewuh juga mempengaruhi penilian pegawai dari atasan kepada bawahan atau penilian bawahan terhadap atasan (Bestari 2010), dengan masalah tersebut peneliti perlu menguji apakah ewuh pakewuh berpengaruh terhadap kinerja APIP inspektorat.

Ukuran kinerja auditor bukanlah kepuasan auditi atau pihak yang meminta audit, melainkan kepatuhan terhadap standar audit. Kinerja auditor inspektorat dapat dipengaruhi oleh faktor integritas, faktor ini dipengaruhi oleh kepribadian auditor dalam kehidupan sehari-hari dalam melakukan audit. Dalam menjaga integritas auditor inspektorat antara lain dengan memberiksan sanksi yang tegas kepada auditor yang terbukti menerima gratifikasi dari auditi (Cahyono et al. 2015). Kinerja auditor inspektorat dipengaruhi oleh faktor politik (Irmawan et al. 2013), misalnya temuan-temuan inspektorat yang bernilai tinggi tidak sampai diekspos dikalahkan oleh kebijakan Kepala Daerah, dengan kondisi tersebut inspektorat sangat terkekang oleh kekuasaan (Saing 2015).

Untuk merubah image bahwa Inspektorat impotent dan mandul serta mampu melaksanakan amanah negara maka inspektorat harus diberi indenpendensi. Bentuk indenpendensi adalah meletakan inspektorat tidak dibawah kekuasaan Kepala Daerah, contohnya dimana membuat peraturan yang pejabat dan auditornya merupakan kepanjangan dari inspektorat jenderal departemen dalam negeri berarti bersifat sentralistis, sehingga dalam melaksanakan tugasnya terlepas dari intervensi Kepala Daerah (Saing 2015)

Penelitian ini menganalisis apakah APIP di Inspektorat Daerah dalam melaksanakan tugas berkinerja baik, dengan prilaku ewuh pakewuh dan independensi. Dari permasalahan tersebut sehingga rumusan masalah pada penelitian ini adalah 1) Apakah Independensi pengawas berpengaruh terhadap kinerja APIP Inspektorat Daerah? 2) Apakah Budaya lokal "ewuh pakewuh" pegawai berpengaruh terhadap Kinrja APIP Inspektorat Daerah?

\section{Independensi dan Kinerja}

\section{TINJAUAN TEORETIS}

Pengawasan di pemerintah daerah dilakuakan oleh APIP, dalam perkembangnya terdapat 2 9dua) rumpun jabatan yang ada di APIP Pemerintah Daerah. APIP yang ada di Pemerintah daerah diantaranya Jabatan Fungsional Pengawas Penyelenggaraan Urusan Pemerintahan di Daerah (JFP2UPD) dan Jabatan Fungsional Auditor (JFA). Kedudukan kedua pengawas tersebut mempunyai peran yang sama yaitu sebagai pelaksana teknis fungsional pengawasan intern di bawah Aparat Pengawasan Intern Pemerintah (APIP).

Pengawas internal pemerintah di daerah secara umum dilakukan oleh inspektorat. Inspektorat daerah memiliki tantangan dalam kinerja yang dilakukan karena auditor memiliki peran yang sangat besar. Auditor harus memiliki sifat 
independen dengan mengambil keputusan tidak berdasarkan kepentingan klien, pribadi, maupun pihak lainnya, melainkan berdasarkan fakta dan bukti yang berhasil dikumpulkan selama penugasan. Pernyataan profesi dalam Standar profesi audit internal adalah "Fungsi audit internal harus ditempatkan pada posisi yang memungkinkan fungsi tersebut memenuhi tanggungjawabnya". Dengan pernyataan standar profesi ini, organisasi auditor dan para auditornya bertanggung jawab untuk selalu bersikap independen, sehingga apa yang menjadi pendapat, kesimpulan, dan rekomendasi dari hasil pemeriksaan tidak memihak oleh pihak manapun.

Auditor memiliki independensi tinggi maka kinerjanya seorang auditor akan menjadi lebih baik (Trisnaningsih 2007 ) hal ini dibuktikan dalam sebuah penelitian yang dilakukan (Putri and Suputra 2013) yang menyimpulkan bahwa semakin tinggi sikap independensi, seorang auditor maka kinerja yang dihasilkan akan semakin tinggi. Akan tetapi seorang auditor akan tidak memiliki prilaku independensi karena berbagai alasan, alasan utama adalah pengelolaan struktur organisasi yang buruk, selain itu adanya switching of auditors bertujuan untuk meningkatkan kualitas (Mohamed and Habib 2013).

Independensi seorang auditor dapat tergangu ketika seorang auditor berhubungan dengan kelompok politik (Irmawan et al. 2013), jumlah biaya audit (Davis and Hollie 2008) terlalu lama dalam hubungan partner audit (Schelker 2013). Pemberlakuan hukum yang ketat bisa menyebabkan seorang auditor berprilaku independen. (Yu 2011) Sedangkan penelitian (Lowe et al. 1999) menyebutkan Independensi dari fihak manajemen cendrung akan berpengaruh negatif terhadap kinerja seorang auditor. Semakin tinggi independensi pengawas pemerintah dalam melakukan pengawasan, maka hasil pemeriksaannya akan sesuai dengan fakta yang sebenarnya sehingga pada akhirnya kinerja auditor akan semakin baik, dari penjelasan tersebut diatas dapat di tarik sebuah hipotesis yaitu :

$H_{1}$ : Independensi pengawas akan berpengaruh positif terhadap Kinerja APIP Inspektorat di Solo Raya.

\section{Ewuh Pakewuh dan Kinerja}

Ewuh pakewuh dapat muncul akibat individu sudah mengenal atau banyak menerima suatu kebaikan dari orang lain sehingga bagi individu akan sulit untuk menolak atau mengabaikan permintaan orang tersebut, bahkan pendapat orang tersebut. Perasaan ewuh pakewuh juga bisa muncul dikarenakan adanya faktor perbedaan usia. Ewuh pakewuh biasanya cenderung di hadapi orang yang lebih muda terhadap orang yang lebih tua atau kepada orang yang memiliki jabatan atau pengaruh dalam organisasi dan masyarakat.

Pengaruh budaya birokrasi ewuh pakewuh menjadikan sistem pengendalian intern tidak efektif, walaupun dalam situasi tertentu dapat memunculkan sikap asertif yang penuh kehatihatian dari bawahan terhadap atasan (kondisional dan situasional) (Soeharjono 2011). Ewuh pakewuh, penilaian yang digunakannya sebagai instrumen penilaian kinerja, dapat disimpulkan bahwa ewuh pakewuh menyebabkan seseorang pimpinan yang memiliki kecenderungan untuk canggung menerima penilaian dari bawahannya dan sebaliknya (Bestari 2010) dan pengaruh kuat budaya dan hubungan sosial dalam organisasi menyebabkan manajemen kontrol tidak dapat bermanfaat 
(Tsamenyi et al. 2008) Sehingga dari penjelasan tersebut dapat di tarik sebuah hipotesis yaitu :

$\mathrm{H}_{2}$ : Budaya lokal "Ewuh pakewuh" akan berpengaruh negatif terhadap profesionalisme Pengawas Internal Inspektorat di Solo Raya.

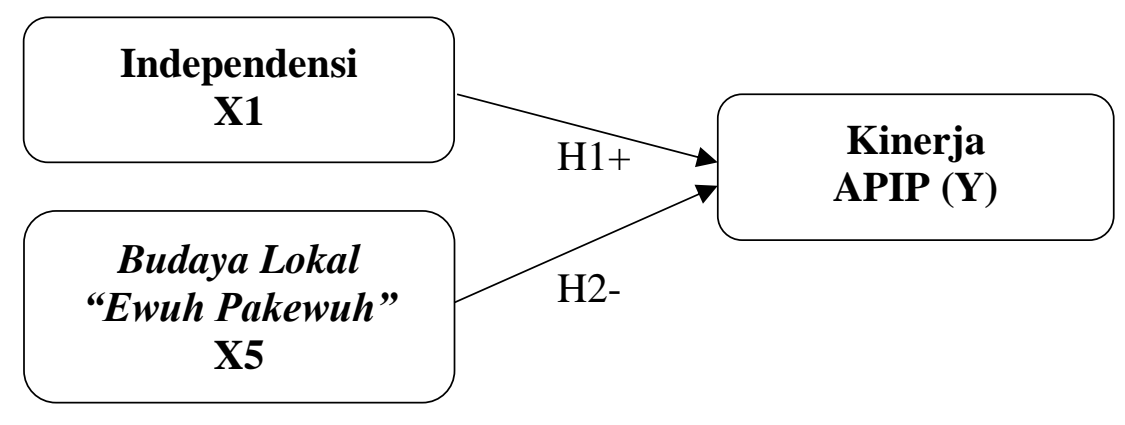

\section{Gambar 1. Kerangka Berfikir}

Berdasarkan dari uraian dari hipotesis diatas, maka sebagai kerangka awal dari penelitian ini dapat dilhat pada Gambar 1

\section{METODE PENELITIAN}

Objek dalam penelitian adalah APIP Inspektorat Daerah di wilayah Solo Raya (Surakarta, Sukoharjo, Klaten, Boyolali, Sragen, Karanganyar dan Wonogiri) yang terdiri dari Auditor dan Pengawas Penyelenggaraan Urusan Pemerintahan di Daerah (P2UPD). Penelitian dilakukan di wilayah ini dikarena faktor pertama, wilayah Soloraya merupakan wilayah yang memiliki kemiripan dalam kebudayaan dan prilaku masyarakat, kedua Inspektorat kabupaten/kota di wilayah Soloraya setiap bulan mengadakan pertemuan rutin membahas masalah-masalah pengawasan daerah dan persamaan persepsi mengenai peraturan-peraturan dan implementasinya pada pengawasan di daerah.

Penelitian ini mengabil sempling dengan menggunakan teknik nonprobability sampling dengan menggunakan teknik Purposive sampling yaitu pengambilan sampling dengan pertimbangan tertentu (Sekaran and Bougie 2013). Kriteria pemilihan sampel adalah APIP yang mempunyai pengalaman pengawasan sekurang-kurangnya 1 tahun dan APIP sudah tersertifikasi sebagai pengawas dan bukan merupakan pegawai struktural di inspektorat.

Data diperoleh dengan menggunakan instrumen kuesioner yang diberikan kepada APIP yang bekerja pada instansi inspektorat daerah di wilayah Solo Raya

Dalam penelitian ini, variabel dependen (Y) yang digunakan adalah kinerja APIP Inspektorat di wilayah Solo Raya sedangkan variabel independennya terdiri dari independensi (X1) dan budaya lokal "ewuh pakewuh" (X2). Independensi (X1) Dalam semua hal yang berkaitan dengan pekerjaan pemeriksaan, organisasi pemeriksa dan pemeriksa, harus bebas dalam sikap mental dan penampilan dari gangguan pribadi, gangguan ekstern. APIP juga harus menjaga independensinya dan kredibilitas laporan audit (Lin 2004). Semua item pertanyaan diukur pada skala Likert 1 sampai 6. Budaya Lokal "Ewuh Pakewuh" (X2) Indikator-indikator untuk mengukur variabel ewuh pakewuh antara lain a) Invidualitas; b) Rentang kekuasaan; c) 
Menghindari ketidakpastian; d) Maskulinitas (Hofstede 1984); f) Keselarasan; g) Keterikatan; h) Otonomi; i) Profesionalitas (Gray 1988 ). Semua item pertanyaan diukur pada skala Likert 1 sampai 6.

Kinerja Pegawai (Y) Didefinisikan sebagai suatu ukuran yang dapat digunakan untuk menetapkan perbandingan hasil pelaksanaan tugas, tanggungjawab yang diberikan oleh organisasi pada periode tertentu dan relatif dapat digunakan untuk mengukur profesionalisme atau kinerja organisasi. Hasil kerja yang dicapai oleh seseorang dalam melaksanakan tugasnya sesuai dengan tanggung jawab yang diberikan padanya, dan menjadi salah satu tolak ukur yang digunakan untuk menentukan apakah suatu pekerjaan yang dilakukan akan baik atau sebaliknya (Kalbers and Fogarty 1995). Pengalaman audit, kemampuan dan pengetahuan auditor tontang akuntansi pemerintahan dan standar akuntansi pemerintahan dan standar audit, menjadi tolak ukur dalam pengetahuan dan profesionalisme auditor (Bonner and Lewis 1990 ). Semua item pertanyaan diukur pada skala Likert 1 sampai 6

\section{Model Analisis Data}

Model analisis yang digunakan untuk menganalisis pengaruh variabel independen terhadap variabel dependen adalah model regresi linier berganda. Model yang digunakan dalam penelitian ini disajikan dalam persamaan sebagai berikut:

$$
\text { Performance }=\alpha+\beta 1 \mathrm{IP}+\beta 2 \mathrm{EP}+\mathrm{e}
$$

Dimana:

$\begin{array}{lll}\text { PROF } & : & \text { Kinerja APIP } \\ \text { a } & : & \text { Nilai intercept } \\ \beta 1-\beta 5 & : & \text { Koefisien regresi } \\ \text { IP } & : & \text { Independensi } \\ \text { EP } & : & \text { Budaya Lokal “Ewuh Pakewuh" } \\ \text { e } & : & \text { error (variabel lain yang tidak dijelaskan dalam model) }\end{array}$

\section{Data Penelitian}

\section{PEMBAHASAN}

Data penelitian yang digunakan dalam penelitian ini merupakan data primer yang diperoleh dengan menggunakan daftar pertanyaan (kuesioner) yang telah disebarkan kepada pengawas Inspektorat Daerah di Solo Raya yang terdiri dari 1 (satu) Kota yaitu Kota Surakarta dan 6 (enam) Kabupaten yaitu Kabupaten Sukoharjo, Kabupaten Klaten, Kabupaten Boyolali, Kabupaten Sragen, Kabupaten Karanganyar, dan Kabupaten Wonogiri. Jumlah kuesioner yang disebar dalam penelitian ini berjumlah 175 kuesioner dengan asumsi untuk masing-masing Inspektorat Kota/Daerah berjumlah 25 kuesioner. Kuesioner yang kembali dari proses penyebaran pada wilayah Solo Raya adalah 169 kuesioner dan kuesioner yang digunakan dalam penelitian ini sebanyak 166 kuesioner.

\section{Uji Instrumen Data dan Uji Normalitas Data}

Berdasarkan proses pengujian validitas dan reliabilitas, maka diperoleh semua valid dan reliable Tabel 1 dan Tabel 2 
Tabel 1. Uji Validitas

\begin{tabular}{ccccc}
\hline No. Item & Independensi & Ewuh Pakewuh & Profesionalisme & Keterangan \\
\hline 1 & .597 & .599 & .741 & Valid \\
2 & .522 & .543 & .584 & Valid \\
3 & .551 & .665 & .720 & Valid \\
4 & .685 & .766 & .535 & Valid \\
5 & .513 & .550 & .604 & Valid \\
6 & .523 & .700 & .772 & Valid \\
7 & .512 & 7.50 & & Valid \\
8 & - & .557 & & Valid \\
\hline
\end{tabular}

Sumber : data diolah, 2019

Tabel 2. Uji Reliabilitas

\begin{tabular}{ccl}
\hline No Item & $\begin{array}{c}\text { Cronbach's } \\
\text { Alpha if Item } \\
\text { Deleted }\end{array}$ & Keterangan \\
\hline Ind1 & .670 & Reliable \\
Ind2 & .646 & Reliable \\
Ind3 & .651 & Reliable \\
Ind4 & .656 & Reliable \\
Ind5 & .675 & Reliable \\
Ind6 & .675 & Reliable \\
Ind7 & .651 & Reliable \\
Ep1 & .617 & Reliable \\
Ep2 & .623 & Reliable \\
Ep3 & .607 & Reliable \\
Ep4 & .634 & Reliable \\
Ep5 & .656 & Reliable \\
Ep6 & .659 & Reliable \\
Ep7 & .638 & Reliable \\
Ep8 & .648 & Reliable \\
Kin1 & .659 & Reliable \\
Kin2 & .653 & Reliable \\
Kin3 & .656 & Reliable \\
Kin4 & .661 & Reliable \\
Kin5 & .675 & Reliable \\
Kin6 & .663 & Reliable \\
\hline
\end{tabular}

Sumber : data diolah, 2019

Uji asumsi klasik penelitian menggunakan uji normalitas, uji multikolinieritas, dan uji heteroskedastisitas. Hasil pengujian data dalam penelitian ini lolos dari uji asumsi klasik yang meliputi normalitas, multikolinieritas, dan heteroskedastisitas. Secara lengkap hasil pengujian asumsi klasik dapat dilihat pada Tabel 3, 4 dan scatterplot pada Gambar 2. 
Tabel 3. Uji Normalitas

\begin{tabular}{|c|c|c|}
\hline & & $\begin{array}{l}\text { Unstandardize } \\
\text { d Residual }\end{array}$ \\
\hline \multicolumn{2}{|l|}{$\mathrm{N}$} & 166 \\
\hline \multirow{2}{*}{$\begin{array}{l}\text { Normal } \\
\text { Parameters }\end{array}$} & Mean & .0000000 \\
\hline & Std. Deviation & 3.15072189 \\
\hline \multirow{3}{*}{$\begin{array}{l}\text { Most } \\
\text { Differences }\end{array}$} & Extreme Absolute & .079 \\
\hline & Positive & .052 \\
\hline & Negative & -.079 \\
\hline \multicolumn{2}{|c|}{ Kolmogorov-Smirnov Z } & 1.020 \\
\hline \multicolumn{2}{|c|}{ Asymp. Sig. (2-tailed) } & .249 \\
\hline
\end{tabular}

Sumber : data diolah, 2019

Tabel 3. Uji Multikolinieritas

\begin{tabular}{|c|c|c|c|}
\hline \multirow{2}{*}{ Model } & \multicolumn{2}{|c|}{ Collinearity Statistics } & \multirow[t]{2}{*}{ Keterangan } \\
\hline & Tolerance & VIF & \\
\hline Independensi & .982 & 1.019 & $\begin{array}{l}\text { Bebas } \\
\text { multikolinearitas }\end{array}$ \\
\hline Ewuh Pakewuh & .982 & 1.019 & $\begin{array}{l}\text { Bebas } \\
\text { multikolinearitas }\end{array}$ \\
\hline
\end{tabular}

Sumber : data diolah, 2019

Gambar 2. Uji Heteroskedastisitas

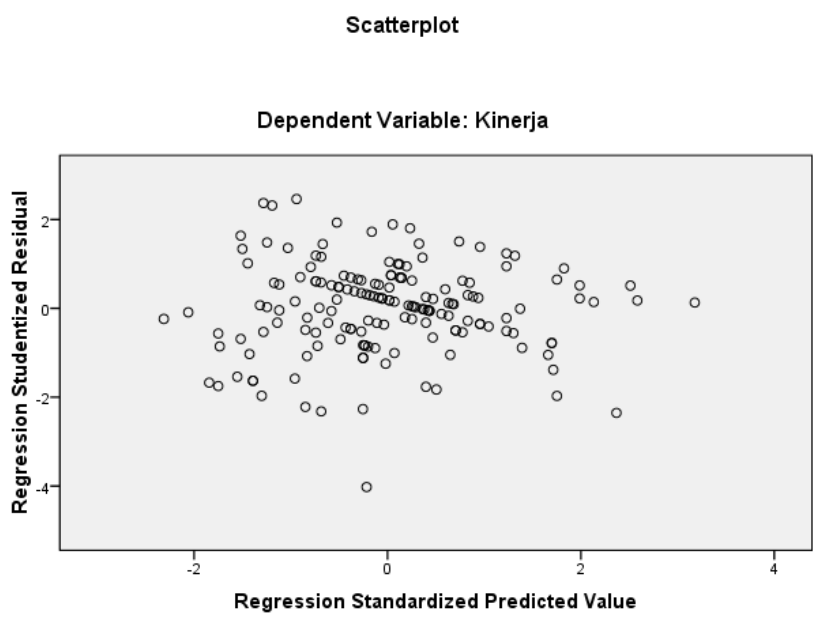

Sumber : data diolah, 2019

\section{Analisis Regresi Berganda}

Hasil pengujian atas model regresi berganda untuk menguji hipotesis menggunakan SPSS 16 dengan menggunakan model persamaan yang telah disusun. Signifikansi level yang digunakan untuk menguji hipotesis adalah $1 \%$ dan $5 \%$. Hasil regresi disajikan pada Tabel 4. 
Tabel 4. Hasil Regresi

\begin{tabular}{lllllll}
\hline Keterangan & $\begin{array}{l}\text { Prediksi } \\
\text { Signifikan }\end{array}$ & $\boldsymbol{\beta}$ & Coefficients & $\begin{array}{l}\text { nilai } \\
\text { test }\end{array}$ & Sig \\
\hline $\begin{array}{l}\text { Constant } \\
\text { Independensi }\end{array}$ & + & 22.740 & & 9.498 & $0.000^{\star *}$ \\
$\begin{array}{l}\text { Ewoh Pakewoh } \\
\text { Overall }\end{array}$ & - & 0.460 & 0.388 & 5.637 & $0.000^{\star *}$ \\
$\begin{array}{l}\text { significance } \\
\text { Jumlah sempel }\end{array}$ & model & $0.000^{*}$ & -0.213 & -0.361 & -5.253 & $0.000^{* *}$ \\
$\begin{array}{l}\text { Adjusted R Square } \\
\text { Nilai F-test }\end{array}$ & 166 & & & & \\
\hline
\end{tabular}

Catatan : indpendensi dan kinerja $\left(\mathrm{H}_{1}\right)$ signifikan pada level 1 persen, ewuh pakewuh dan kinerja $\left(\mathrm{H}_{2}\right)$ signifikan pada level 1 persen..

*Highly significant at 1 per cent level; ** significant at 5 per cent level, $\mathrm{n}=166$

Sumber : data diolah, 2019

Berdasarkan Tabel 4, nilai-nilai tersebut terlihat bahwa independensi (X1) berpengaruh signifikan terhadap terhadap kinerja APIP di Inspektorat Daerah pada tingkat signifikansi t lebih kecil dari a $=0,01$ yakni $t(X 1)=0,000$. Budaya lokal "ewuh pakewuh" (X2) juga berpengaruh terhadap kinerja APIP di Inspektorat Daerah pada tingkat signifikansi $t$ lebih kecil dari $a=0,01$ yakni $t(X 2)=0,000$. Hasil pengujian ini juga mendukung hipotesis $\mathrm{H}_{1}$ dan, $\mathrm{H}_{2}$

Besarnya nilai adjusted $\mathrm{R}^{2}$ dengan menggunakan persamaan regresi adalah 0,234 pada tabel 4. Nilai ini menunjukkan bahwa $23,4 \%$ variasi kinerja APIP Inspektorat Daerah dapat dijelaskan oleh variasi dari independensi dan budaya lokal "ewuh pakewuh", sedangkan sisanya sebesar 76,6\% dipengaruhi oleh faktor-faktor lain yang tidak masuk ke dalam model penelitian. Selain itu berdasarkan nilai uji F pada tabel 4 untuk uji simultan diperoleh sebesar 26,163 dengan tingkat signifikansi sebesar 0,000. Niali signifikansi uji $F$ lebih kecil dari 0,05 maka dapat disimpulkan bahwa model regresi yang digunakan untuk mengetahui pengaruh independensi dan budaya lokal "ewuh pakewuh" pada profesionalisme pengawas adalah layak (fit).

\section{Pembahasan}

Penelitian ini menguji pengaruh Independensi dan Budaya lokal "ewuh pakewuh" terhadap kinerja APIP Inspektorat Daerah diwilayah Solo Raya. Berdasarkan Tabel 4 persamaan regresi dapat ditulis seperti dibawah ini.

Performance $=22.740+0.460 \beta 1-0.213 \beta 2$

Secara keseluruhan, hasil pengujian hipotesis dengan menggunakan regresi berganda dapat dilihat pada Tabel 5 
Tabel 5. Ringkasan Hasil Pengujian Hipotesis

\begin{tabular}{llll}
$\begin{array}{l}\text { Kode } \\
\text { Hipotesis }\end{array}$ & Hipotesis & Hasil \\
\hline $\mathrm{H}_{1}$ & $\begin{array}{l}\text { Independensi pengawas akan berpengaruh positif terhadap } \\
\text { profesionalisme Pengawas Intrnal Inspektorat di }\end{array}$ & Diterima \\
& $\begin{array}{l}\text { Subosukowonosraten. } \\
\mathrm{H}_{2}\end{array}$ & $\begin{array}{l}\text { Budaya lokal “ewuh pakewuh" akan berpengaruh negatif } \\
\text { terhadap profesionalisme Pengawas Internal Inspektorat di }\end{array}$ & \\
& Subosukowonosraten. & \\
& & & \\
\end{tabular}

\section{Pengaruh Independensi terhadap Profesionalisme Pengawas Interen Inspektorat}

Dengan menggunakan kedua model regresi $\mathrm{H}_{1}$ diterima, ini dapat dilihat nilai independensi memiliki nilai $\beta 5=0,460$ dengan tingkat signifikansi sebesar 0,000 $(\operatorname{sig}<0,05)$, sehingga hipotesis kedua $\left(\mathrm{H}_{1}\right)$ diterima. dengan demikian Independensi berpengaruh positif terhadap profesionalisme pengawas internal pemerintah di wilayah Solo Raya. Hasil penelitian ini sejalan dengan penelitian (Trisnaningsih 2007 ) yang menyatakan bahwa auditor memiliki independensi tinggi maka kinerjanya seorang auditor akan menjadi lebih baik, (Putri and Suputra 2013) juga menyimpulkan bahwa semakin tinggi sikap independensi, seorang auditor maka kinerja yang dihasilkan akan semakin tinggi.

Dengan hasil tersebut berarti semakin independen seorang pengawas internal pemerintah maka akan semakin mempengaruhi profesionalnya. Dapat disimpulkan adanya hubungan antara independensi pengawas internal pemerintah dengan profesionalisme pegawai, bahwa seorang pengawas memiliki independensi tinggi maka dia tidak akan mudah terpengaruh dan tidak mudah dikendalikan oleh pihak lain dalam mempertimbangkan fakta yang dijumpai dalam pemeriksaan dan dalam merumuskan dan menyatakan pendapatnya sehingga akan mempengaruhi tingkat pencapaian pelaksanaan suatu pekerjaan yang semakin baik atau dengan kata lain kinerjanya akan menjadi lebih baik.

\section{Pengaruh Budaya lokal "Ewuh Pakewuh" terhadap Profesionalisme Pengawas Internal Inspektorat}

Pengujian hipotesis kedua $\left(\mathrm{H}_{2}\right)$ memiliki nilai $\beta 5=-0,213$ dengan tingkat signifikansi sebesar 0,000 (sig<0,05), sehingga hipotesis kedua $\left(\mathrm{H}_{2}\right)$ diterima. Jadi dengan menggunakan 2 (dua) model regresi yang digunakan dalam penelitian ini variabel Budaya lokal "ewuh pakewuh" mempunyai pengaruh negatif pada profesionalisme pengawas internal inspektorat di Solo Raya.

Sejalan dengan penelitian yang dilakukan oleh (Soeharjono 2011) pengaruh budaya birokrasi ewuh pakewuh menjadikan sistem pengendalian intern tidak efektif. Ewuh pakewuh, yang digunakan sebagai penilaian instrumen penilaian kinerja, dapat disimpulkan bahwa ewuh pakewuh menyebabkan seseorang pimpinan yang memiliki kecenderungan untuk canggung menerima penilaian dari bawahannya dan sebaliknya (Bestari 2010) dan pengaruh kuat budaya dan hubungan sosial dalam organisasi menyebabkan manajemen kontrol tidak dapat bermanfaat (Tsamenyi et al. 2008). 


\section{PENUTUP}

Penelitian ini bertujuan untuk mengetahui pengaruh Independensi dan Budaya lokal "ewuh pakewuh" terhadap kinerja APIP di Inspektorat Daerah di Solo Raya. Berdasarkan hasil penelitian ini, maka dapat diambil kesimpulan Independensi berpengaruh positif dan signifikan terhadap profesionalisme pengawas internal inspektorat daerah di Solo Raya, independensi yang dimiliki akan menjamin yang bersangkutan untuk melakukan audit secara profesional. Independensi pengawas semakin baik, maka akan semakin baik profesionalisme pengawas inspektorat. Budaya lokal "ewuh Pakewuh" berpengaruh negatif terhadap profesionalisme pengawas Internal Inspektorat Daerah di Solo Raya. Budaya "ewuh pakewuh" yang tinggi akan menyebabkan tingkat profesionalisme pengawas internal inspektorat daerah menjadi rendah.

Evaluasi atas hasil penelitian ini harus mempertimbangkan keterbatasan yang mungkin mempengaruhi hasil penelitian, di antaranya sulitnya mengendalikan responden, sehingga penelitian selanjutnya dapat menggunakan metode lain seperti wawancara langsung kepada pengawas di inspektorat atau setidaknya dapat memastikan pihak responden untuk mebendakan fungsi pengawasan masingmasing. Penelitian ini menggunakan pengukuran kuesioner yang mungkin menimbulkan bias persepsi atas pertanyaan-pertanyaan yang ada dikuesioner. Penelitian ini menggunakan instrumen penelitian yang diadopsi dari penelitian yang dilakukan di luar Indonesia, kemudian diadaptasi lagi untuk disesuaikan dalam konteks sektor publik, sehingga masih mungkin ditemukan beberapa kelemahan. Hal ini karena adanya situasi dan kondisi yang berbeda baik antara di Indonesia dan di luar negeri maupun antara konteks sektor privat dan sektor publik.

Berdasarkan hasil penelitian yang telah dilakukan maka diajukan saran. Penelitian mendatang sebaiknya melakukan sebuah penelitian dengan menggunakan metode wawancara langsung untuk mengumpulkan data penelitian agar dapat mengurangi adanya kelemahan terkait internalal validity. Budaya lokal "ewuh pakewuh" hanya merupakan satu jenis budaya yang ada di birokrasi pemerintah, penelitian selanjutanya peneliti menyarankan budaya-budaya lokal yang banyak ada sipemerintahan misalnya budaya lokal "alon-alon waton kelakon" yang mungkin banyak dialami masyarakat dalam menerima pelayanan dari pemerintah.

\section{DAFTAR PUSTAKA}

Agustina, L. 2011. Pengaruh Konflik Peran, Ketidakjelasan Peran, dan Kelebihan Peran terhadap Kepuasan Kerja dan Kinerja Auditor (Penelitian pada Kantor Akuntan Publik yang Bermitra Dengan Kantor Akuntan Publik Big Four di Wilayah DKI Jakarta). Jurnal Akuntansi 1 (1):40.

Beehr, T., A,, J. Walsh, T, and T. Taber, D. . 1976. Relationships of stress to individually and organizationally valued states: Higher order needs as a moderator. Journal of applied psychology 61 (1):41.

Bestari, P. 2010. The Employers Performance Evaluation (A Case At Secretariat West Java Local Government). Bandung: Universitas Padjadjaran Bandung.

Bonner, S. E., and B. L. Lewis. 1990 Determinants of auditor expertise. . Journal of Accounting Research:1-20. 
Cahyono, A. D., A. F. Wijaya, and T. Domai. 2015. Pengaruh kompetensi, independensi, obyektivitas, kompleksitas tugas, dan integritas auditor terhadap kualitas hasil audit. Reformasi 5 (1):1-12.

Davis, S. M., and D. Hollie. 2008. The impact of nonaudit service fee levels on investors' perception of auditor independence. Behavioral Research In Accounting 20 (1):31-44.

Deis Jr, D. R., and G. A. Giroux. 1992. Determinants of audit quality in the public sector. Accounting Review:462-479.

Djafar, W. 2012. Memotong Warisan Birokrasi Masa Lalu, Menciptakan Demarkasi Bebas Korupsi. Jurnal Legislasi Indonesia 8 (2).

Fanani, Z., R. A. Hanif, and B. Subroto. 2008. Pengaruh Struktur Audit, Konflik Peran, Dan Ketidakjelasan Peran Terhadap Kinerja Auditor Jumal Akuntansi dan Keuangan Indonesia 5 (2).

Fisher, R. T. 2001. Role stress, the type A behavior pattern, and external auditor job satisfaction and performance Behavioral Research In Accounting 13 (1):143-170.

Fogarty, T. J., J. Singh, G. K. Rhoads, and R. K. Moore. 2000. Antecedents and Consequences of Burnout in Accounting: Beyond the Role Stress Model. Behavioral Research. in Accounting 12:31.

Gahlan, V. S., and K. Singh. 2014. The Effect of Role Overload and Role Ambiguity on Job Performance of IT Professionals in India. IUP Journal of Management Research 13 (3).

Gray, S. J. 1988 Towards a Theory of Cultural Influence on the Development of Accounting Systems Internally Abacus 24: 1-15.

Harsudi, C. 2012. Restrukturisasi Inspektorat, Syarat Mutlak Pemberantasan Korupsi di Instansi Pemerintah Citizen Journalism for Anti Corruption (CJAC).

Hofstede, G. 1984. Cultural dimensions in management and planning. Asia Pacific journal of management 1 (2):81-99.

Irmawan, Y., M. Hudaib, and R. Haniffa. 2013. Exploring Perceptions of Auditor Independence in Indonesia. ,. Journal of Islamic Accounting and Business Research 4 (2):173 -202.

Kahn, R. L., D. Katz, and J. S. Adams. 1980. Conflict, Ambiguity, and Overload: Three Elements in Job Stress", In Katz, D, Kahn, R, Adams, J (Eds), The Study of Organizations San Francisco, CA: Jossey-Bass.

Kahn, R. L., D. M. Wolfe, R. P. Quinn, J. D. Snoek, and R. A. Rosenthal. 1964. Organizational stress: Studies in role conflict and ambiguity. New York, Wiley.

Kalbers, L. P., and T. J. Fogarty. 1995. Professionalism and its consequences-a study of internal auditors. Auditing A Journal of Practice and Theory 14 (1):64-86.

Karmadi, A. D. 2007. Budaya Lokal Sebagai Warisan Budaya Dan Upaya Pelestariannya. Yogyakarta: Balai Pelestarian Sejarah dan Nilai Tradisional Yogyakarta.

Koo, C. M., \& Sim, H. S. 1999. On the role conflict of auditors in Korea. Accounting Auditing \& Accountability Journal, 12 (2):206-219.

Lee Larson, L. 2004. Internal auditors and job stress. Managerial Auditing Journal 19 (9 ):1119-1130. 
Lin, Z. J. 2004 Auditor's responsibility and independence: Evidence from China. Research in Accounting Regulation 17:167-190.

Lowe, D. J., M. A. Geiger, and K. Pany. 1999. The effects of internal audit outsourcing on perceived external auditor independence Auditing: A Journal of Practice $\mathcal{E}$ Theory 18 (s-1):7-26.

Mardiasmo. 2002. Akuntansi Sektor Publik. Yogyakarta: Andi.

Mohamed, D. M., and M. H. Habib. 2013. Auditor independence, audit quality and the mandatory auditor rotation in Egypt. Education, Business and Society: Contemporary Middle Eastern Issues 6 (2):116-144.

Pranoto, S. W. 2005. Budaya Daerah Dalam Era Desentralisasi Jurnal Humaniora 17 (3):236 - 242.

Putri, K. M. D., and I. D. G. Suputra. 2013. Pengaruh Independensi, Profesionalisme, Dan Etika Profesi Terhadap Kinerja Auditor Pada Kantor Akuntan Publik Di Bali. E-Jurnal Akuntansi Universitas Udayana 4 (1):39-53.

Rizwan, M., M. A. Tariq, S. Hussain, R. M. Rashid, M. S. Hussain, and I. H. Khawar. 2014. Antecedents of job stress and its impact on job satisfaction Asian Journal of Empirical Research 3 (2):175-190.

Rizzo, J. R., R. J. House, and S. I. Lirtzman. 1970. Role conflict and ambiguity in complex organizations. Administrative Science Quarterly:150-163.

Saing, C. 2015. Menuntut Independensi Inspektorat. Jambi: Inspektorat Daerah Kota JAmbi.

Schelker, M. 2013. Auditors and Corporate Governance: Evidence from the Public Sector KYKLOS 66 (2):275-300.

Sekaran, U., and R. Bougie. 2013. Research Method for Business, A Skill Building Approach. . New York: John Willey\&Son Inc

Smith, K. J., G. S. Everly, and T. R. Johns. 1993 The Role of Stress Arousal in the Dynamics of the Stressor-to-Iuness Process among Accountants Contemporary Accounting Research 9 (2 ):432-449.

Soeharjono, H. 2011. Pengaruh Budaya Birokrasi “Ewuh-Pakewuh" Terhadap Efektivitas Sistem Pengendalian Intern Jurnal Ilmu Administrasi VIII (3).

Sutardi, T. 2007. Antropologi: Mengungkap Keragaman Budaya. Bandung: PT Grafindo Media Pratama.

Trisnaningsih, S. 2007 Independensi auditor dan komitmen organisasi sebagai mediasi pengaruh pemahaman good governance, gaya kepemimpinan dan budaya organisasi terhadap Kinerja auditor. . In Simposium Nasional Akuntansi X. Makasar, 1-56.

Tsamenyi, M., I. Noormansyah, and S. Uddin. 2008. Management controls in familyowned businesses (FOBs): A case study of an Indonesian family-owned University. . In Accounting Forum 32 (1):62-74

Utami, I., and E. Nahartyo. 2013 The Effect of Type a Personality on Auditor Burnout: Evidence from Indonesia. Accounting and Taxation (Forthcoming) 5 (2).

Viator, R. E. 2001. The association of formal and informal public accounting mentoring with role stress and related job outcomes. Accounting, Organizations and Society 26 (1):73-93. 
Wibowo, S. A., H. Amir, and R. Ilhamuddin. 2013. Pengaruh Kohesivitas Kelompok Dan Ewuh Pakewuh Terhadap Pemberian Teguran Atasan Kepada Bawahan.

$\mathrm{Yu}$, H. C. 2011. Legal systems and auditor independence. Review of Accounting Studies 16 (2):377-411.

Yuli, S., S,E. 2002. Hubungan Patron Klien Pedagang "Nasi Kucing" Dikotayogyakarta Jurnal Penelitian Humaniora 7 (1). 